\title{
Soft drink consumption in Sri Lankan adolescents
}

\author{
Nilantha Ratnayake ${ }^{1}$ and Lilani Ekanayake ${ }^{2, *}$ \\ ${ }^{1}$ Institute of Oral Health, Maharagama, Sri Lanka: ${ }^{2}$ Faculty of Dental Science, University of Peradeniya, \\ Peradeniya 200400, Sri Lanka
}

Submitted 24 August 2011: Final revision received 3 February 2012: Accepted 24 February 2012: First published online 12 April 2012

\begin{abstract}
Objective: To determine the factors associated with sugar-sweetened soft drink consumption in adolescents from Sri Lanka.

Design: A cross-sectional study where the data were collected by means of a self-administered questionnaire.

Setting: Government, private and international schools in the Colombo district of Sri Lanka.

Subjects: Adolescents aged 17 years attending sixty-five schools.

Results: Overall $82 \%$ consumed sugar-sweetened soft drinks once weekly or more often, while $77 \%$ and $48 \%$ consumed sugar-sweetened carbonated drinks and sugar-sweetened fruit drinks once weekly or more often. Being a boy $(\mathrm{OR}=1 \cdot 44$; $95 \%$ CI $1 \cdot 02,2 \cdot 03)$, attending a private/international school $(\mathrm{OR}=4 \cdot 12 ; 95 \% \mathrm{CI}$ $1 \cdot 94,8 \cdot 75)$, mother's level of education (OR $=1 \cdot 53 ; 95 \%$ CI $1 \cdot 03,2 \cdot 28)$ and father's occupation (middle level: $\mathrm{OR}=2 \cdot 39$; $95 \%$ CI 1.63, 3.52; upper level: $\mathrm{OR}=2 \cdot 48$; $95 \%$ CI $1 \cdot 35,4 \cdot 56$ ) were independently associated with the consumption of sugarsweetened soft drinks.

Conclusions: The majority of adolescents in this sample consumed sugar-sweetened beverages once weekly or more often. It was evident that some sociodemographic factors were associated with the consumption of these drinks.
\end{abstract}

Keywords
Soft drinks
Adolescents
Sri Lanka
Evidence indicates that the consumption of soft drinks is increasing worldwide. Compared with 2009, the global consumption of soft drinks increased by $4 \%$ in 2010 with a per capita consumption of 81 litres. The highest growth in the soft drinks market in the year 2010 was observed in Asia, with India and China reporting growth rates of $16 \%$ and $14 \%$ respectively ${ }^{(1)}$.

Soft drink consumption varies according to age, and particularly the consumption of sugar-sweetened carbonated beverages is highest during adolescence ${ }^{(2)}$. Wang et al $^{(3)}$ reported that on any given day, $84 \%$ of American adolescents consume sugar-sweetened beverages and the average intake is $30 \mathrm{oz} / \mathrm{d}$. Bere et al. ${ }^{(4)}$ found that $63 \%$ of Norwegian adolescents consume sugar-sweetened carbonated soft drinks twice weekly or more. Owing to their high content of added sugar, soft drinks contribute a significant proportion of the daily energy intake in adolescents. It has been reported that sweetened soft drinks accounted for $13 \%$ of the daily energy intake in American adolescents and of this 55\% came from sugarsweetened carbonated drinks ${ }^{(3)}$.

Consumption of sugar-sweetened beverages has detrimental effects on the general health and oral health of adolescents. A systematic review on the intake of sugarsweetened beverages and weight gain provided strong evidence for the independent role of sugar-sweetened beverage consumption, particularly sugar-sweetened carbonated drinks, in promoting weight gain and obesity in children and adolescents ${ }^{(5)}$. Moreover, the consumption of sugar-sweetened soft drinks is strongly associated with dental caries ${ }^{(6)}$, while the consumption of carbonated beverages is considered a risk factor for dental ero$\operatorname{sion}^{(7)}$.

Many researchers have assessed the determinants of soft drink consumption in adolescents. However, it is noteworthy that these studies have been confined mainly to the developed countries. Although there is evidence to indicate that soft drink consumption is growing in Asian countries such as India $^{(8)}$, there is a paucity of information related the determinants of soft drink consumption in Asian adolescents. Therefore the aim of the present study was to determine the factors associated with consumption of sugarsweetened soft drinks in adolescents from Sri Lanka.

\section{Methods}

The present study was a component of a broader study on the prevalence and risk indicators for tooth wear in 17-year-olds in Sri Lanka. It has been mentioned in studies 
of tooth wear that it is relevant to select the late teen group because the aetiological agents of tooth wear have then had sufficient time to act on the dentition ${ }^{(9)}$. This was the reason for selecting 17 -year-olds as the study population. Ethical approval for the study was obtained from the Ethical Review Committee of the Faculty of Medicine, University of Colombo. Permission to conduct the study was obtained from the Provincial Director of Education and the principals of the respective schools. Written informed consent was obtained from the students and their parents. The methodology and results pertaining to the factors associated with soft drink consumption are described herein.

The target group of the present study was 17-year-old students attending government, private and international schools in the Colombo district of Sri Lanka. The formula for estimating a population proportion with absolute precision was used to calculate the sample size. A review of the literature indicated that there were no data on the prevalence of tooth wear for Sri Lanka. Therefore to calculate the sample size, the prevalence was considered as $50 \%$. When the expected population proportion is unknown, the safest choice for population proportion is considered to be $50 \%{ }^{(10)}$. Accordingly, the minimum sample size required for the present study using a prevalence of $50 \%$ at the confidence interval of $95 \%$ and accepting a sampling error of $5 \%$ was 384. A two-stage cluster sampling technique combined with the probability proportional to size technique was used to select the sample. As the cluster sampling technique was used it was necessary to take into account the design effect, which was considered as 2 for the present study. After compensating for the design effect and for non-responses, the minimum sample size required was 998. Milosevic et al. ${ }^{(9)}$ have stated that in studies of tooth wear it is necessary to include large sample numbers to capture sufficient numbers of cases for extensive analysis. Taking into account the logistics and time available it was decided to include 1200 students in the present study.

The sample was selected in two stages. Students who had had their 17 th but not their 18th birthday were in the 12th grade class. The average size of the class (fifteen students) was considered as the cluster size and accordingly eighty clusters were necessary to obtain the sample $(1200 / 15=80)$. In the first stage of sampling, the sampling unit was the school and the eighty clusters were identified from fifty-one, eleven and three government, private and international schools, respectively, according to the probability proportional to size technique. The probability proportional to size technique allows each government, private and international school to be selected according to the proportion of students in those schools. In the second stage fifteen students who satisfied the age criterion were randomly selected from each cluster. Those students residing outside the Colombo district and who were foreign nationals were excluded from the sample.
Data were collected by means of a validated, pre-tested, self-administered questionnaire. The expert opinion of consultants in public health/restorative dentistry was sought when developing the questionnaire. The draft questionnaire was reviewed by the consultants and modifications were made based on their recommendations. This process assured content validity. The construct validity was assessed by determining the agreement between responses to questions that assessed a similar construct. The reliability of the questionnaire was assessed by the test-retest method. To test the reliability ten students were asked to complete the questionnaire at two different points in time. The questionnaire was pre-tested among fifty 17-year-old students from a different district to prevent contamination of the study sample. Modifications to the questionnaire were made based on the results of the pre-test. Consumption of soft drinks was assessed according to the frequency of consumption and recorded on a 7-point scale: daily, once in $2 \mathrm{~d}$, once in $3 \mathrm{~d}$, once in 4-6 d, once a week, less than once a week and never. In the Sri Lankan context soft drinks include: (i) carbonated drinks, (ii) natural fruit juices, (iii) sugar-sweetened fruit drinks such as squashes and cordials and (iv) sports drinks, where carbonated drinks and sugar-sweetened fruit drinks such as squashes and cordials are considered as sugarsweetened soft drinks. The questionnaire was administered in the classroom and in the presence of the first author, which enabled the students to clarify any doubts.

The SPSS statistical software package version $13 \cdot 0$ (SPSS Inc., Chicago, IL, USA) was used for data analysis. Although the frequency of consumption was recorded on a 7-point scale, the numbers in certain categories were low. Therefore for the purpose of analysis, the frequency of consumption of all soft drinks excluding sports drinks was categorized into two groups: (i) less than once weekly and (ii) once weekly or more often. The latter group included those who consumed soft drinks daily as well. Those who stated that they never consumed soft drinks were excluded from the analysis. The $\chi^{2}$ test was used to determine the associations between categorical variables. Having checked for multi-collinearity, those variables that were significantly associated $(P<0.05$ level) with the frequency of sugar-sweetened soft drink consumption in the bivariate analysis were included in a binary multiple logistic regression (forward conditional) model to determine the independent associations with the dependent variable (frequency of sugar-sweetened soft drink consumption).

\section{Results}

Of the 1200 students selected to be included in the sample, seventy-seven declined to participate which gave an overall response rate of $93.6 \%$. There was a slight preponderance of girls $(53 \%)$ in the sample. The majority of the sample 
Table 1 Frequency of soft drink consumption: adolescents aged 17 years, Colombo district of Sri Lanka

\begin{tabular}{|c|c|c|c|c|c|c|}
\hline \multirow[b]{2}{*}{ Type of soft drink } & \multicolumn{2}{|c|}{ Never } & \multicolumn{2}{|c|}{ Once weekly or more } & \multicolumn{2}{|c|}{ Less than once weekly } \\
\hline & $n$ & $\%$ & $n$ & $\%$ & $n$ & $\%$ \\
\hline Any sugar-sweetened drinks ( $n 1123)$ & 1 & $0 \cdot 1$ & 915 & $81 \cdot 5$ & 207 & $18 \cdot 4$ \\
\hline Sugar-sweetened carbonated drinks ( $n$ 1123) & 1 & $0 \cdot 1$ & 865 & $77 \cdot 0$ & 257 & $22 \cdot 9$ \\
\hline Sugar-sweetened fruit drinks ( $n$ 943) & 20 & $2 \cdot 2$ & 457 & $48 \cdot 4$ & 466 & $49 \cdot 4$ \\
\hline Natural fruit juices ( $n$ 978) & 42 & $4 \cdot 3$ & 516 & $52 \cdot 7$ & 420 & $43 \cdot 0$ \\
\hline
\end{tabular}

Table 2 Associations between sugar-sweetened soft drink consumption and selected variables: adolescents aged 17 years, Colombo district of Sri Lanka

\begin{tabular}{|c|c|c|c|c|c|}
\hline \multirow[b]{3}{*}{ Variable } & \multicolumn{4}{|c|}{ Sweetened soft drink consumption } & \multirow[b]{3}{*}{$P$} \\
\hline & \multicolumn{2}{|c|}{ Less than once weekly } & \multicolumn{2}{|c|}{ Once weekly or more* } & \\
\hline & $n$ & $\%$ & $n$ & $\%$ & \\
\hline Gender & & & & & 0.004 \\
\hline Girls ( $n$ 592) & 128 & $21 \cdot 6$ & 464 & $78 \cdot 4$ & \\
\hline Boys $(n 530)$ & 79 & $14 \cdot 9$ & 451 & $85 \cdot 1$ & \\
\hline Ethnicity & & & & & $0 \cdot 36$ \\
\hline Sinhala $(n 910)$ & 175 & $19 \cdot 2$ & 735 & $80 \cdot 8$ & \\
\hline Tamil $(n 111)$ & 18 & $16 \cdot 2$ & 93 & $83 \cdot 8$ & \\
\hline Moor $(n 100)$ & 14 & $14 \cdot 0$ & 86 & $86 \cdot 0$ & \\
\hline Father's occupationt & & & & & $<0.001$ \\
\hline Lower (n 237) & 87 & $36 \cdot 7$ & 150 & $63 \cdot 3$ & \\
\hline Middle $(n 606)$ & 86 & $14 \cdot 2$ & 520 & $85 \cdot 8$ & \\
\hline Upper ( $n$ 143) & 18 & $12 \cdot 6$ & 125 & $87 \cdot 4$ & \\
\hline Mother's education (years) & & & & & $<0.001$ \\
\hline$\leq 10(n 608)$ & 142 & $23 \cdot 4$ & 466 & $76 \cdot 6$ & \\
\hline$>10(n 428)$ & 48 & $11 \cdot 2$ & 380 & $88 \cdot 8$ & \\
\hline Type of school & & & & & $<0.001$ \\
\hline Government ( $n$ 925) & 198 & $21 \cdot 4$ & 727 & $78 \cdot 6$ & \\
\hline Private/international ( $n$ 197) & 9 & $4 \cdot 6$ & 188 & $95 \cdot 4$ & \\
\hline Engages in regular sports activities & & & & & $0 \cdot 80$ \\
\hline Yes $(n 76)$ & 13 & $17 \cdot 1$ & 63 & $82 \cdot 9$ & \\
\hline No $(n$ 1013) & 185 & $18 \cdot 3$ & 828 & $81 \cdot 7$ & \\
\hline Does regular exercise & & & & & 0.05 \\
\hline Yes (n 192) & 26 & $13 \cdot 5$ & 166 & $86 \cdot 5$ & \\
\hline No $(n 921)$ & 179 & $19 \cdot 4$ & 742 & $80 \cdot 6$ & \\
\hline
\end{tabular}

*Includes daily consumers as well.

tFather's occupation: lower = unskilled/skilled labour, low-level business categories; middle = clerical, technical, middle-level business categories; upper = professional, managerial, upper-level business categories.

attended government schools (82\%) while $14 \%$ and $4 \%$ attend private and international schools, respectively.

The frequency of soft drink consumption is given in Table 1 . Overall nearly $82 \%$ consumed sugar-sweetened soft drinks once weekly or more often and of these $2 \%$ were daily consumers. Seventy-seven per cent and $48 \%$ respectively consumed sugar-sweetened carbonated drinks and sugar-sweetened fruit drinks once weekly or more often. Consumption of sports drinks was very low; only $5 \%$ reported that they consumed these drinks. Consumption of sports drinks was associated with engaging in exercise at least three times weekly. Also, a significantly higher percentage of boys participated in sports and exercise than girls (results not shown). Nearly 53\% stated that they consumed natural fruit juice once weekly or more often. Bivariate analysis revealed that sugar-sweetened soft drink consumption was associated with gender, father's occupation, mother's level of education, type of school attended and engaging in regular exercise (Table 2). Table 3 shows the factors that were independently associated with the consumption of sugar-sweetened soft drinks once weekly or more often. Being a boy $(\mathrm{OR}=1 \cdot 44 ; 95 \%$ CI $1 \cdot 02,2 \cdot 03)$, attending a private/international school $(\mathrm{OR}=4 \cdot 12 ; 95 \% \mathrm{CI} 1 \cdot 94,8 \cdot 75)$, mother's level of education (OR $=1 \cdot 53 ; 95 \%$ CI $1 \cdot 03,2 \cdot 28)$ and father's occupation (middle level: $\mathrm{OR}=2 \cdot 39$; $95 \%$ CI $1 \cdot 63$, 3.52; upper level: $\mathrm{OR}=2 \cdot 48 ; 95 \%$ CI $1.35,4.56)$ were associated with the consumption of these drinks.

\section{Discussion}

To the best of knowledge, the present study is the first to assess soft drink consumption in Sri Lankan adolescents. 
Table 3 Multiple logistic regression (forward conditional) analysis for sugar-sweetened soft drink consumption ( $n$ 948): adolescents aged 17 years, Colombo district of Sri Lanka

\begin{tabular}{llcr}
\hline Variable & OR & $95 \% \mathrm{Cl}$ & $P$ \\
\hline $\begin{array}{l}\text { Sex } \\
\quad \text { Girls }\end{array}$ & 1.00 & & \\
$\quad$ Boys & 1.44 & $1.02,2.03$ & 0.03 \\
$\begin{array}{l}\text { Type of school } \\
\quad \text { Government }\end{array}$ & 1.00 & & \\
$\quad \begin{array}{l}\text { Private/international } \\
\text { Mother's education (years) }\end{array}$ & 4.12 & $1.94,8.75$ & $<0.001$ \\
$\quad$ I10 & 1.00 & & \\
$\quad \begin{array}{l}>10 \\
\text { Father's occupation }\end{array}$ & 1.53 & $1.03,2.28$ & 0.03 \\
$\quad$ Lower & 1.00 & & \\
$\quad$ Middle & 2.39 & $1.63,3.52$ & $<0.001$ \\
$\quad$ Upper & 2.48 & $1.35,4.56$ & 0.003 \\
\hline
\end{tabular}

Dependent variable, sugar-sweetened soft drink consumption, dichotomized as 0 if less than once weekly and 1 if once weekly or more (includes daily consumers as well).

Consumption patterns with regard to four types of soft drinks were assessed: carbonated drinks, natural fruit juices, sugar-sweetened fruit drinks such as squashes/ cordials and sports drinks. The majority of adolescents (82\%) consumed sugar-sweetened soft drinks once weekly or more often, but only $2 \%$ consumed these drinks daily. The latter figure is considerably lower than what has been reported for adolescents from other developing countries. It has been reported that 7-17\% of Chinese adolescents ${ }^{(11)}$ and $24 \%$ of Palestinian adolescents consume soft drinks daily ${ }^{(12)}$.

Sugar-sweetened carbonated drinks were the most common type of drink consumed by the students in our study, with $77 \%$ indicating that they consumed these drinks once weekly or more often. Recent studies conducted in other developing countries also indicate that the consumption of sugar-sweetened carbonated drinks is high among adolescents. It has been reported that $48 \%$ of adolescent girls in Hyderabad, India consume sugar-sweetened carbonated drinks 1-2 times per week $^{(13)}$. In fact, the above data indicate that the frequency of consumption of sugar-sweetened carbonated drinks among adolescents in developing countries is comparable to that of adolescents from developed societies. According to Grimm et al. ${ }^{(14)} 86 \%$ of American adolescents consume sweetened-carbonated soft drinks once weekly or more, while $63 \%$ of Norwegian adolescents consume the same twice weekly or more according to Bere et $a l^{(4)}$. Like in many developing countries, carbonated drinks are available even in the most remote areas of Sri Lanka. Moreover aggressive advertising campaigns are carried out throughout the country, particularly by multinational soft drink companies, to promote their consumption. It may be that the above factors are associated with the consumption of sugar-sweetened carbonated drinks in Sri Lanka. None of the students in the present study consumed diet carbonated drinks. On the other hand, $27 \%$ of Norwegian adolescents $^{(4)}$ and 15\% of American 8-13-year-olds ${ }^{(14)}$ reported consumption of diet carbonated drinks. Diet soft drinks are available in only a few supermarkets in the urban areas of Sri Lanka and unlike the regular varieties, their consumption is not promoted by soft drink companies. Therefore many may not be aware of the availability of diet carbonated drinks. This may be a plausible explanation why diet drinks are not popular in Sri Lanka. Taylor et $a l .{ }^{(8)}$ reported that only $34 \%$ of outlets they surveyed in Delhi, India sold diet Pepsi and Coca Cola and those outlets were mainly in the affluent areas, whereas in London all outlets surveyed stocked both varieties of Pepsi and Coca Cola. Only $5 \%$ of the present sample reported that they consume sports drinks. In contrast, $16 \%$ of high-school students in the US consume sports drinks daily $^{(15)}$. Consumption of these drinks was significantly higher in those who did regular exercise in our study (data not shown). Ranjit et al. ${ }^{(16)}$ have also found that consumption of sports drinks in adolescents is associated with physical activity.

Availability of soft drinks in school is strongly associated with their consumption $^{(14)}$. It is noteworthy that of the sixty-five schools included in the present study, soft drinks were sold in all except one. The Ministry of Health in Sri Lanka introduced the 'Healthy School Canteen Policy' a few years ago where schools are encouraged to provide wholesome, nutritious foods/drinks and to restrict the sale of 'junk food/drinks'. However it is evident from the present study that this policy is yet to be implemented in most schools in the Colombo district of Sri Lanka. On the other hand, in their study on soft drink consumption in Norwegian adolescents Bere et $a l .{ }^{(4)}$ reported that carbonated soft drinks were available only in one of the thirty-three schools included in their sample. Implementation of policies to restrict the sale of sugar-sweetened soft drinks in schools has shown to reduce the consumption of such drinks significantly ${ }^{(17)}$.

Sri Lankan boys consumed more sugar-sweetened soft drinks than girls. This is consistent with the findings from other studies ${ }^{(4,12,14,15)}$. It has been shown that there is a significant correlation between sugar-sweetened soft drink consumption and physical activity in adolescent boys ${ }^{(18)}$. The results of the present study revealed that a significantly higher percentage of boys were engaged in regular sports and exercise than girls. Therefore the gender differences in physical activity may be one of the possible reasons for the gender difference in sugar-sweetened soft drink consumption. Moreover, in our study father's occupation status was positively associated with the frequency of sugarsweetened soft drink consumption. Similar findings have been reported for adolescents from Central and Eastern European countries. However in European countries with developed economies ${ }^{(19)}$, soft drink consumption is lower among adolescents of higher parental occupation status. Parental occupation status is considered a proxy for socioeconomic status of adolescents. Therefore it is reasonable 
to assume in developing countries that the consumption of sugar-sweetened beverages is higher among high socioeconomic groups because they are more affordable to those groups compared with low socio-economic groups. Food habits of children, particularly those from developed countries, are dependent on the level of education of the mother. Children and young people whose mother had a lower level of education were less likely to follow a healthy dietary pattern ${ }^{(20)}$. However, conforming to the findings of Al Sabbah et $a l^{(12)}$, the present study found that the consumption of soft drinks was positively associated with the mother's level of education. It may be that the mother's level of education reflects the socio-economic status of the adolescents of the present study. Therefore adolescents whose mother had a higher level of education may have been able to afford soft drinks more than those whose mother had a low level of education.

Dietary assessments are usually based on self-reports and the present study also used the same methodology to obtain information on soft drink intake. Measurement bias may have influenced the results of the study as there is a possibility that the students may have selectively under- or over-reported the frequency of consumption. This is a limitation of the study. Also $12-15 \%$ of the students did not respond to the questions on the frequency of consumption of natural fruit juices and squashes/cordials. It is plausible that these adolescents may have either misunderstood the questions or were non-consumers and therefore did not respond to the questions. However, it is noteworthy that all adolescents had responded to these two questions during the pre-testing of the questionnaire.

\section{Conclusion}

It is evident from the present results that the majority of adolescents in this sample consumed sugar-sweetened beverages once weekly or more often. Therefore there is a need for nutrition education to limit the consumption of sugar-sweetened soft drinks in Sri Lankan adolescents.

\section{Acknowledgements}

This study was supported by grant RG/2007/HS/11 from the National Science Foundation of Sri Lanka. The authors declare that there are no conflicts of interest. The study was conducted by N.R. under the guidance and supervision of L.E. for the degree of MD in Community Medicine, Post Graduate Institute of Medicine, University of Colombo, Sri Lanka.

\section{References}

1. News System (2011) Global soft drink consumption increases in 2010. http://www.ceepackaging.com/2011/08/09/globalsoft-drinks-consumption (accessed December 2011).
2. Storey ML, Forshee RA \& Anderson PA (2006) Beverage consumption in the US population. I Am Diet Assoc 106, 1992-2000.

3. Wang YC, Bleich SN \& Gortmaker SL (2008) Increasing caloric contribution from sugar sweetened beverages and $100 \%$ fruit juices among US children and adolescents, 1988-2004. Pediatrics 121, 1604-1614.

4. Bere E, Glomnes ES, te Velde SJ et al. (2008) Determinants of adolescents' soft drink consumption. Public Health Nutr 11, 49-56.

5. Malik VS, Schulze MB \& Hu FB (2006) Intake of sugarsweetened beverages and weight gain: a systematic review. Am J Clin Nutr 84, 274-288.

6. Levine RS, Nugent ZJ, Rudolf MC et al. (2007) Dietary patterns, tooth brushing habits and caries experience of school children in west Yorkshire, England. Community Dent Health 24, 82-87.

7. El Karim IA, Sanhouri NM, Hashim NT et al. (2007) Dental erosion among 12-14 year old school children in Khartoum: a pilot study. Community Dent Health 24, 176-180.

8. Taylor FC, Satija A, Khurana S et al. (2011) Pepsi and Coca Cola in Delhi, India: availability, price and sales. Public Health Nutr 14, 653-660.

9. Milosevic A, Bardsley PF \& Taylor S (2004) Epidemiological studies of tooth wear and dental erosion in 14-year-old children in North West England. Part 2. The association of diet and habits. Br Dent J 197, 479-483.

10. Lwanga SK \& Lemeshow S (1991) Sample Size Determination in Health Studies. A Practical Manual. Geneva: WHO.

11. Shi Z, Lien N, Kumar BN et al. (2005) Socio-demographic differences in food habits and preferences of school adolescents in Jiangsu Province, China. Eur J Clin Nutr 59, 1439-1448.

12. Al Sabbah H, Vereecken C, Kolsteren P et al. (2007) Food habits and physical activity patterns among Palestinian adolescents: findings from the national study of Palestinian school children (HBSC-WBG2004). Public Health Nutr 10, 739-746.

13. Rao D, Vijayapushpam T, Subba Rao G et al. (2007) Dietary habits and effects of two different educational tools on nutrition knowledge of school going adolescents girls in Hyderabad, India. Eur J Clin Nutr 61, 1081-1085.

14. Grimm GC, Harnack L \& Story M (2004) Factors associated with soft drink consumption in school-aged children. J Am Diet Assoc 104, 1244-1249.

15. Centers for Disease Control and Prevention (2011) Beverage consumption among high school students - United States, 2010. Morbid Mortal Wkly Rep 60, 778-780; available at http://www.cdc.gov/mmwr/preview/mmwrhtml/mm6023 a22.htm

16. Ranjit N, Evans MH, Byrd-Williams C et al. (2010) Dietary and activity correlates of sugar sweetened beverage consumption among adolescents. Pediatrics 126, e754-e761.

17. Cradock AL, McHugh A, Mont-Ferguson H et al. (2011) Effect of school district policy change on consumption of sugar-sweetened beverages among high school students, Boston, Massachusetts, 2004-2006. Prev Chronic Dis 8, A74.

18. Vagstrand K, Linne Y, Karlsson J et al. (2009) Correlates of soft drink and fruit juice consumption among Swedish adolescents. Br J Nutr 101, 1541-1548.

19. Vereecken CA, Inchley J, Subramanian SV et al. (2005) The relative influence of individual and contextual socio-economic status on consumption of fruit and soft drinks among adolescents in Europe. Eur J Public Health 15, 224-232.

20. Aranceta J, Perez-Rodrigo C, Ribas L et al. (2003) Sociodemographic and life style determinants of food patterns in Spanish Children and adolescents: the enKid study. Eur J Clin Nutr 57, Suppl. 1, S40-S44. 